\title{
Concomitant alveolar haemorrhage and cytomegalovirus infection in a patient with systemic lupus erythematosus
}

\author{
Y.L. Kwong, K.L. Wong, I.T.M. Kung, ${ }^{1}$ P.C.K. Chan and W.K. Lam \\ Department of Medicine and ${ }^{1}$ Department of Pathology, University of Hong Kong, Queen Mary Hospital, \\ Hong Kong.
}

\begin{abstract}
Summary: We report a 37 year old Chinese woman with systemic lupus erythematosus complicated by concomitant cytomegalovirus pneumonia and alveolar haemorrhage. The cytomegalovirus pneumonia may have been causally related to the alveolar haemorrhage.
\end{abstract}

\section{Introduction}

Although alveolar haemorrhage complicating systemic lupus erythematosus (SLE) is well described, its pathogenesis remains controversial. We describe a patient with SLE and alveolar haemorrhage who had concomitant cytomegalovirus pneumonia.

\section{Case report}

A 37 year old Chinese woman first presented in June 1985 with ankle swelling. Investigations revealed anaemia and proteinuria. A renal biopsy was performed after which the patient was put on prednisone $60 \mathrm{mg} /$ day and azathioprine $100 \mathrm{mg} /$ day. She subsequently developed progressive renal function impairment and was referred to our unit. Haemoglobin before admission was $7.9 \mathrm{~g} / \mathrm{dl}$.

On admission, the patient complained of haemoptysis and dyspnoea at rest. Physical examination revealed that she was pale with bilateral pitting ankle oedema. Tachypnoea and bilateral basal crepitations were present.

Investigations showed: haemoglobin $4.5 \mathrm{~g} / \mathrm{dl}$ (normochromic and normocytic), white blood cell count $8.0 \times 10^{9} / 1$, platelet count $167 \times 10^{9} / 1$, erythrocyte sedimentation rate (ESR) $85 \mathrm{~mm} / \mathrm{h}$, reticulocyte count $8.0 \%$, urea $32.8 \mathrm{mmol} / \mathrm{l}$, creatinine $0.158 \mathrm{mmol} / \mathrm{l}$, antinuclear factor (ANF) titre 1:1250, anti-DNA antibodies positive, $\mathrm{C}_{3}$ $21 \mathrm{mg} / \mathrm{dl}$ (normal 60-130), $\mathrm{C}_{4} 7 \mathrm{mg} / \mathrm{dl}$ (normal 1360 ). Cryoglobulin was negative. Urine protein was 1.5 g. Arterial blood gases showed $\mathrm{PaO}_{2} \quad 6 \mathrm{kPa}$

Correspondence: Y.L. Kwong M.B., B.S., M.R.C.P.(UK) Accepted: 16 April 1987 (normal 10-13) and $\mathrm{PaCO}_{2} 4.12 \mathrm{kPa}$ (normal 4.7 6.0). Urinalysis revealed telescopic sediments. Bilateral mottlings were found in her chest X-ray. Her renal biopsy on review showed diffuse proliferative lupus glomerulonephritis.

The patient continued to deteriorate with increasing dyspnoea and haemoptysis. Chest $\mathrm{X}$-ray showed progressive mottlings (Figure 1a). Her sputum revealed abundant haemosiderin laden macrophages. Five units of blood were transfused resulting in a haemoglobin of $10.4 \mathrm{~g} / \mathrm{dl}$. Prednisone was decreased from a daily dose of $60 \mathrm{mg}$ to $20 \mathrm{mg}$. Azathioprine was stopped. Three days later there was improvement with clearing up of the mottlings in her chest X-ray (Figure 1b).

Meanwhile, her renal function showed concomitant deterioration. The plasma urea increased to $42.5 \mathrm{mmol} / \mathrm{l}$ and creatinine to $0.35 \mathrm{mmol} / \mathrm{l}$. Intravenous pulse methylprednisolone $1 \mathrm{~g}$ daily was given for three days. She responded with gradual improvement of renal function to normal urea $(6.4 \mathrm{mmol} / \mathrm{l})$ and creatinine $(0.114 \mathrm{mmol} / \mathrm{l})$ levels 2 weeks later. The haemoglobin remained at $9.5 \mathrm{~g} / \mathrm{dl}$.

Clinical improvement continued with ESR returning to normal and titre of ANF falling to $1: 50$. While clinically her disease was inactive, she suddenly developed another episode of haemoptysis, fever and dyspnoea 4 weeks after her initial presentation. A concomitant drop of haemoglobin to $6 \mathrm{~g} / \mathrm{dl}$ resulted. Chest X-ray showed bilateral mottlings (Figure 2a). Bronchoscopic biopsy showed features of cytomegalovirus (CMV) infection and intra-alveolar haemorrhage with a lot of haemosiderin laden macrophages (Figure 3). CMV titre rose from $1: 160$ to $1: 640$. She was managed conservatively without further stepping up her

(C) The Fellowship of Postgraduate Medicine, 1988 

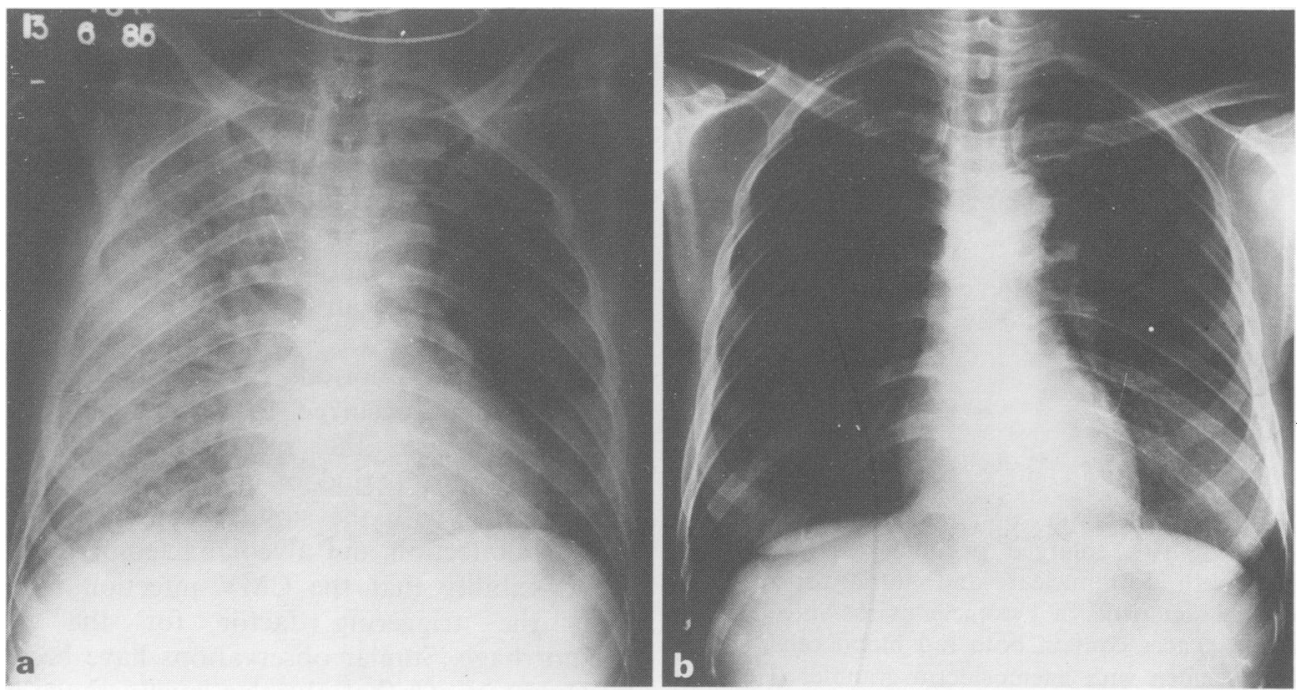

Figure 1 Chest X-ray (a) on admission showing diffuse mottlings affecting predominantly the right lung; (b) 3 days later showing clearing of the shadows.

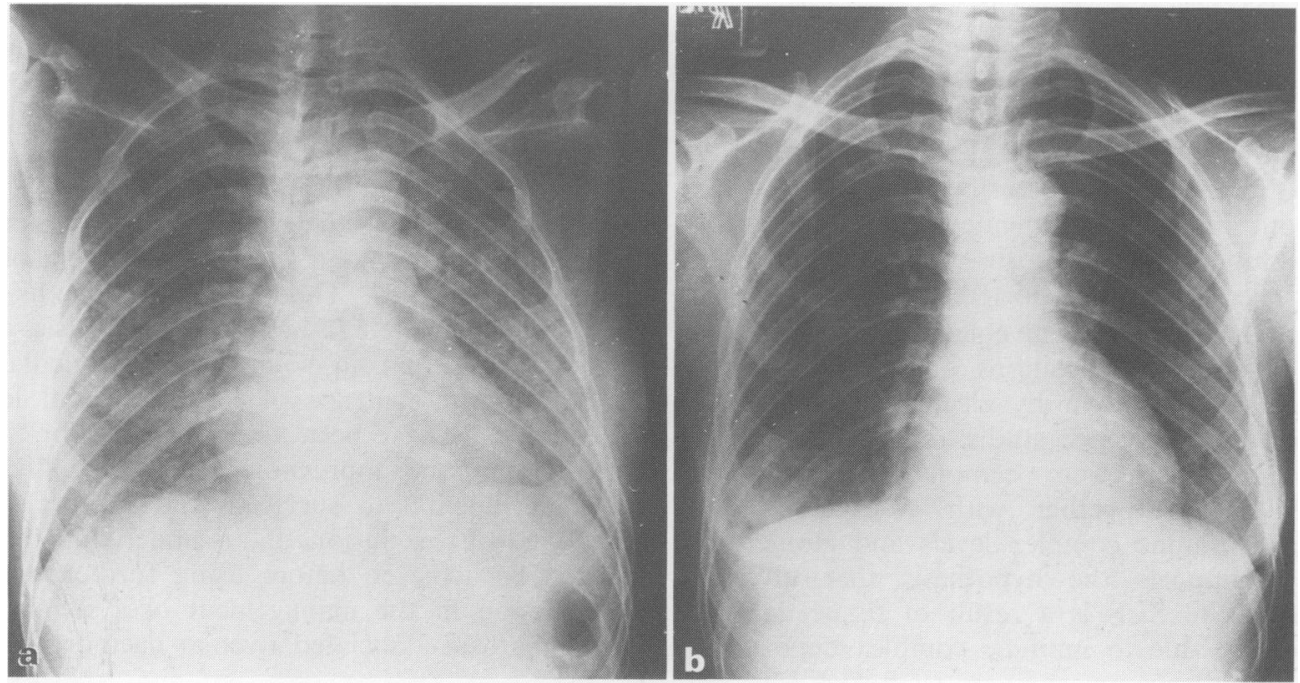

Figure 2 Chest X-ray (a) on relapse of symptoms showing diffuse pulmonary shadows; (b) 2 weeks later showing resolution.

steroids. Her symptoms and chest X-ray changes resolved spontaneously after 2 weeks (Figure $2 b$ ).

At follow-up 18 months later she was maintained on prednisone $5 \mathrm{mg} /$ day. Her chest X-ray remained clear and her renal function remained normal.

\section{Discussion}

Alveolar haemorrhage systemic lupus erythematosus is uncommon, though well described. The clinical presentation of the sudden development of diffuse pulmonary infiltrates associated with a drop in haemoglobin and hypoxaemia was seen in $2 \%$ of patients with pulmonary disease in one series. ${ }^{1}$ Alveolar haemorrhage is usually abrupt and typically accompanied by other evidence of active systemic disease such as fever, arthritis, hypocomplementaemia and glomerulonephritis. ${ }^{2}$ Post-mortem 


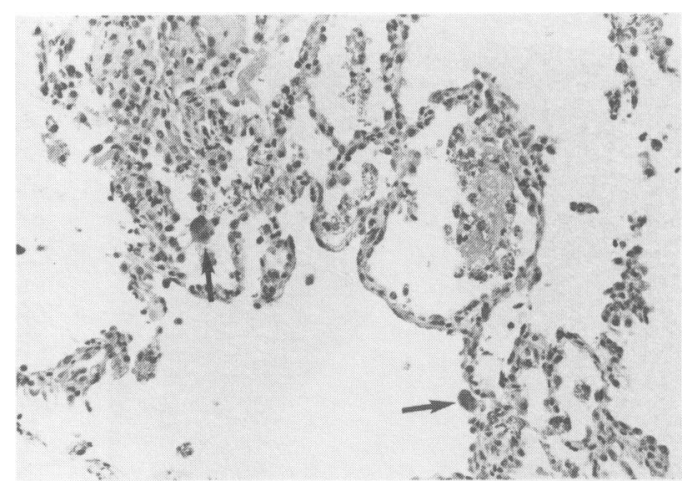

Figure 3 Photomicrograph of transbronchial lung biopsy showing two enlarged pneumocytes (arrows) containing both intranuclear and intracytoplasmic inclusions characteristic of cytomegalovirus infection. The alveolar spaces contain both red blood cells and macrophages laden with haemosiderin granules (H. \& E. $\times 275)$.

studies, however, reported an incidence varying between $24-66 \%, 3,4$ The extent of pulmonary lesions ranged from a few focal subpleural petechial haemorrhages to massive haemorrhages involving an entire lung. ${ }^{4}$ How these cases presented in life was unknown. It is possible that only a minority presented in the manner described above, as so far only about 30 well documented clinical cases of systemic lupus erythematosus-associated alveolar haemorrhage have been reported. ${ }^{5}$

The pathogenesis of alveolar haemorrhage in SLE is unknown. Depositions of immunoglobulin and complement shown by electronic microscopy and immunofluorescence studies in alveolar septae and blood vessels were demonstrated in some cases. $^{2,6,7}$ This, together with co-existing high circulating immune complex levels and glomerulonephritis, supports the hypothesis that alveolar haemorrhage in SLE is a result of tissue damage and vasculitis due to immune complex deposition.

\section{References}

1. Carette, S., Macher, A.M., Nussbaum, A. \& Plotz, P.H. Severe, acute pulmonary disease in patients with systemic lupus erythematosus: ten years of experience at the National Institutes of Health. Semin Arthritis Rheum 1984-5, 14: 52-59.

2. Eagen, J.W., Memoli, V.A., Roberts, J.L. et al. Pulmonary haemorrhage in systemic lupus erythematosus. Medicine (Baltimore) 1978, 57: $545-560$.
Haupt et al., ${ }^{3}$ however, suggested that these immunofluorescence findings might have resulted from non-specific deposition of immunoglobulin and complement secondary to membrane damage arising from infection, infarction or uraemia so that immunofluorescence findings did not often correlate with alveolar haemorrhage. Some studies, ${ }^{8,9}$ moreover, have shown alveolar haemorrhage occurring in the absence of immune complex deposition.

While the first episode of alveolar haemorrhage in our patient occurred in the context of active systemic disease, the second episode occurred apparently in a period of clinical quiescence. This fact together with the simultaneous demonstration of CMV infection and alveolar haemorrhage raises the possibility that the CMV infection may have been the triggering factor for the alveolar haemorrhage. Similar observations have been made by Haupt et al. ${ }^{6}$ that alveolar haemorrhage in SLE may be related to intercurrent infections though they have not specified the types of infection nor attempted to establish a causal relationship between the two. Recently, Carette et al. ${ }^{1}$ described a lupus patient with alveolar haemorrhage due to Legionella infection, showing therefore that infection may be causally related to alveolar haemorrhage.

Reported mortality of systemic lupus erythematosus-associated alveolar haemorrhage reaches $70 \%,{ }^{5}$ despite a standard treatment of large doses of steroid. Though many deaths were undoubtedly related to active systemic disease, it is also possible that in some cases, particularly in those without evidence of immunological lesions, infection may have been a triggering factor, so that further immunosuppression might actually have been detrimental to survival. The authors suggest that vigorous exclusion of an underlying infection should be achieved before using further immunosuppression in the management of systemic lupus erythematosus-associated alveolar haemorrhage.

3. Haupt, H.M., Moore, G.W. \& Hutchins, G.M. The lung in systemic lupus erythematosus. Am J Med 1981, 71: 791-798.

4. Purnell, D.C., Baggenstoss, A.H. \& Olsen, A.M. Pulmonary lesions in disseminated lupus erythematosus. Ann Intern Med 1955, 42: 619-628. 
5. Leatherman, J.W., Davies, S.F. \& Hoidal, J.R. Alveolar haemorrhage syndromes: diffuse microvascular lung haemorrhage in immune and idiopathic disorders. Medicine (Baltimore) 1984, 63: 343-361.

6. Pertschuk, L.P., Moccia, L.F., Rosen, Y. et al. Acute pulmonary complications in systemic lupus erythematosus: immunofluorescence and light microscopic study. Am J Clin Pathol 1977, 68: 553-557.

7. Gould, D.B. \& Soriano, R.Z. Acute alveolar haemorrhage in lupus erythematosus. Ann Intern Med 1975, 83: 836-837.
8. Marino, C.T. \& Pertschuk, L.P. Pulmonary haemorrhage in systemic lupus erythematosus. Arch Intern Med 1981, 141: 201-203.

9. Desnoyers, M.R., Bernstein, S., Cooper, A.G. \& Kopelman, R.I. Pulmonary haemorrhage in lupus erythematosus without evidence of an immunological cause. Arch Intern Med 1984, 144: 1398-1340. 